\title{
Produção da bananeira 'Prata anã'(AAB) em função de diferentes doses e fontes de potássio
}

\author{
José Tadeu Alves da Silva ${ }^{1}$, Rosimeire Dantas Pereira², Inez Pereira Silva ${ }^{3}$, Polyanna Mara de Oliveira
}

\section{RESUMO}

Dentre os nutrientes exigidos pela bananeira, o K é o que mais influencia na produção desta cultura. Este trabalho teve por objetivos comparar os efeitos de duas fontes de $\mathrm{K}$ (cloreto de potássio e sulfato de potássio) sobre a produção, bem como estimar as doses de K para obter a máxima eficiência física (MEF) e econômica (MEE) e determinar o nível crítico de K na folha da bananeira 'Prata anã' (AAB) irrigada, cultivada na região semiárida do norte de Minas Gerais, Brasil. O experimento foi realizado em Latossolo Vermelho-Amarelo (LVA), textura média. Os tratamentos foram originados do fatorial (4 x 2), sendo quatro doses de $\mathrm{K}\left(0,400,800\right.$ e $1200 \mathrm{~kg} /$ ha ano de $\mathrm{K}_{2} \mathrm{O}$ ) e duas fontes de $\mathrm{K}$ ( $\mathrm{KCl}$ e $\mathrm{K}_{2} \mathrm{SO}_{4}$ ), gerando oito tratamentos, que foram distribuídos em blocos ao acaso, com quatro repetições. Não houve diferenças entre os efeitos do $\mathrm{KCl} \mathrm{e}_{2} \mathrm{SO}_{4}$ sobre a produção da bananeira. A análise econômica demonstrou que o $\mathrm{KCl}$ apresentou maior viabilidade para ser utilizado como fonte de K. As doses estimadas para a MEF nos $2^{\circ}$ e $3^{\circ}$ ciclos de produção, utilizando-se o $\mathrm{KCl}$, foram de 827 e $835 \mathrm{~kg} \mathrm{ha}^{-1} \mathrm{ano}^{-1}$ de $\mathrm{K}_{2} \mathrm{O}$, respectivamente. Já para a MEE, as doses foram de 157 e $670 \mathrm{~kg} / \mathrm{ha}$ ano de $\mathrm{K}_{2} \mathrm{O}$, respectivamente. Os níveis críticos foliares de $\mathrm{K}$, obtidos nos $2^{\circ}$ e $3^{\circ}$ ciclos de produção, foram de 2,85 dag kg-1 para a MEF e, para a MEE, de 2,41 e 2,80 dag kg-1, respectivamente.

Palavras-chave: nível crítico, dose econômica, adubação.

\section{ABSTRACT}

\section{Production of banana tree cv. Prata anã (AAB) as a function of different doses and sources of potassium}

Among the nutrients required by the banana tree, the potassium $(\mathrm{K})$ is what most influences the production of the crop. This study aimed to compare the effects of two $\mathrm{K}$ sources, potassium chloride $(\mathrm{KCl})$ and potassium sulfate $\left(\mathrm{K}_{2} \mathrm{SO}_{4}\right)$ on production, and estimate the dose of $\mathrm{K}$ for maximum physical efficiency (MPE) and maximum economic efficiency (MEE), besides determine the critical levels of leaf $K$ for the banana tree, cultivar Prata anã (AAB) irrigated, cultivated in the semi-arid region of northern Minas Gerais State, Brazil. The experiment was conducted in an oxisol, medium texture. The treatments were derived from the factorial $(4 \times 2)$, being four rates of $\mathrm{K}(0,400,800$ and $1200 \mathrm{~kg}$ ha$1 \mathrm{yr}-1$ of $\mathrm{K}_{2} \mathrm{O}$ ) and two $\mathrm{K}$ sources $\left(\mathrm{KCl}_{\text {and }} \mathrm{K}_{2} \mathrm{SO}_{4}\right)$, resulting in eight treatments. These were distributed in randomized blocks with four replications. There were no differences among the effects of $\mathrm{KCl}$ and $\mathrm{K}_{2} \mathrm{SO}_{4}$ on the production of banana. The $\mathrm{KCl}$ showed greater economic viability to be used as a source of $\mathrm{K}$. The estimated doses for MPE of banana in the 2nd and 3rd production cycles using the $\mathrm{KCl}$ were 827 and $835 \mathrm{~kg} \mathrm{ha}^{-1} \mathrm{yr}^{-1}$ of $\mathrm{K}_{2} \mathrm{O}$, respectively, while for MEE, doses were 157 and $670 \mathrm{~kg} \mathrm{ha}^{-1} \mathrm{yr}^{-1}$ of $\mathrm{K}_{2} \mathrm{O}$, respectively. The critical levels of leaf $\mathrm{K}$ obtained in the 2nd and 3rd production cycles were $2.85 \mathrm{dag} \mathrm{kg}^{-1}$ for the MPE and for MEE, the values were 2.41 and $2.80 \mathrm{dag} \mathrm{kg}^{-1}$, respectively.

Key words: Critical level, economic rate, fertilization.

Recebido para publicação em 07/01/2011 e aprovado em 09/11/2011

'Engenheiro Agrônomo, Doutor. EPAMIG (Unidade Regional do Norte de Minas). Caixa Postal 12, 39525-000, Nova Porteirinha-MG., Brasil. E-mail: josetadeu@epamig.br ${ }^{2}$ Graduanda em Agronomia da UNIMONTES, Bolsista de iniciação científica FAPEMIG/EPAMIG, Caixa Postal 12, 39525-000, Nova Porteirinha, MG, Brasil. rosimeire.dantas@yahoo.com.br

${ }^{3}$ Engenheira Agrônoma, Mestranda em Solos e Nutrição de Plantas, Universidade Federal de Lavras, Departamento de Ciência do Solo, Caixa Postal 3037, 37.200-000, Lavras, inezps@yahoo.com.br

${ }^{4}$ Engenheira Agrícola, Doutora. EPAMIG (Unidade Regional do Norte de Minas). Caixa Postal 12, 39525-000, Nova Porteirinha-MG, Brasil. polyanna.mara@epamig.br 


\section{INTRODUÇÃO}

A bananeira é uma cultura que extrai grandes quantidades de nutrientes do solo, sendo a adubação um dos fatores que mais influenciam na produção, bem como na resistência às doenças.

O potássio $(\mathrm{K})$ é o cátion mais abundante na planta, sendo absorvido em grandes quantidades pelas raízes. Tem importante função na translocação e armazenamento de fotoassimilados e na manutenção de água nos tecidos vegetais. O K não faz parte de nenhuma estrutura ou molécula orgânica na planta (Meurer, 2006).

O K é o nutriente exigido em maior quantidade pela bananeira, sendo absorvido na forma de íon $\mathrm{K}^{+}$. A bananeira cultivada em solos com deficiência de K, geralmente, produz cachos pequenos, com frutos finos com baixo peso.

As adubações com K das bananeiras 'Prata anã', cultivadas no norte de Minas Gerais, são calculadas com base em trabalho de Silva \& Borges (2008), no qual as doses de $\mathrm{K}$ recomendadas variam entre 50 e $750 \mathrm{~kg} /$ ha ano de $\mathrm{K}_{2} \mathrm{O}$, dependendo do teor desse nutriente disponível no solo e da produtividade esperada. Diversos trabalhos têm sido realizados com o objetivo de estimar a dose adequada de K para obter alta produtividade na bananeira, dentre eles o de Silva et al. (2003). No referido trabalho, os autores avaliaram o efeito da aplicação de cinco doses de K (0; 200; 400; 800 e 1600 $\mathrm{kg} / \mathrm{ha}$ ano de $\mathrm{K}_{2} \mathrm{O}$ ), em bananeira 'Prata anã', cultivada em solo com alto teor de $\mathrm{K}$ (210 $\left.\mathrm{mg} \mathrm{dm}^{-3}\right)$, utilizando como fonte o $\mathrm{KCl}$. Os efeitos da aplicação do $\mathrm{K}$ no solo sobre a produção da bananeira foram observados somente no $4^{\circ}$ ciclo. Estimou-se que a produção máxima da bananeira $\left(36,6 \mathrm{t} \mathrm{ha}^{-1}\right.$ ano $\left.^{-1}\right)$ ocorreu com a aplicação de $963 \mathrm{~kg} / \mathrm{ha}$ ano de $\mathrm{K}_{2} \mathrm{O}$, promovendo um aumento de $11 \%$ na produção de banana, em relação à testemunha. Em outro estudo realizado por Sousa et al. (2004), a produção máxima da bananeira 'Grand Naine', no $2^{\circ}$ ciclo, foi obtida com aplicação de $933 \mathrm{~kg} \mathrm{ha}^{-1}$ de $\mathrm{K}_{2} \mathrm{O}$. Entretanto, Pinto et al. (2005) não verificaram efeitos significativos da aplicação de K sobre a produção da bananeira 'Pacovan' (AAB), cultivada em solo arenoso com $82 \mathrm{mg} \mathrm{dm}^{-3}$ de $\mathrm{K}$.

Ao avaliar a aplicação de três doses de K $(0 ; 800$ e $1200 \mathrm{~kg} / \mathrm{ha}$ ano) e cinco doses de magnésio (0; 60; 120; 240 e $480 \mathrm{~kg} / \mathrm{ha}$ ano) em bananeira 'Prata anã' irrigada, Silva (2010) verificou que as doses de K aplicadas no solo, no $1^{\circ}$ ciclo, aumentaram, de forma linear, o peso do cacho, o número de frutos por cacho, o número de pencas por cacho e o peso do fruto. No $2^{\circ}$ ciclo, verificou-se que a aplicação de $\mathrm{K}$ elevou somente o número de frutos/ penca. De acordo com o autor, o teor de K disponível no solo apresentava valor de $128 \mathrm{mg} \mathrm{dm}^{-3}$, classificado como alto por Alvarez et al. (1999).
A fonte de $\mathrm{K}$ mais utilizada na cultura da bananeira é o cloreto de potássio $\left(\mathrm{KCl}-58 \%\right.$ de $\left.\mathrm{K}_{2} \mathrm{O}\right)$. De acordo com Ernani et al. (2007), tal fonte apresenta índice salino de 116, com grande tendência de aumento da pressão osmótica da solução do solo. $\mathrm{O} \mathrm{K}$ na forma de $\mathrm{KCl}$ pode ter efeito prejudicial sobre as plantas. Silva et al. (2001) relatam que a aplicação de K afetou o crescimento radicular de Capsicum aпnиит L., por efeito salino do $\mathrm{KCl}$ sobre as raízes, o que permite inferir que a aplicação de altas doses de $\mathrm{KCl}$ podem afetar o crescimento das plantas, por toxicidade do $\mathrm{Cl}$. Por outro lado, esse adubo apresenta a vantagem de ter baixo custo em relação às outras fontes de $\mathrm{K}$.

O sulfato de potássio ( $50 \%$ de $\mathrm{K}_{2} \mathrm{O}$ e $16 \%$ de $\mathrm{S}$ ) é outra fonte que pode ser utilizada na adubação da bananeira. Possui enxofre (S) em sua composição e apresenta índice salino de 46, bem menor que o do $\mathrm{KCl}$. Seu custo, entretanto, é duas vezes maior e a sua solubilidade em água é três vezes menor que a do $\mathrm{KCl}$ (Silva \& Borges, 2008).

Para Malavolta et al. (1997), existe uma relação bem definida entre o crescimento, a produção das culturas e o teor dos nutrientes em seus tecidos. $\mathrm{O}$ conhecimento dos teores de nutrientes nos tecidos permite que, por meio de sua análise, avalie-se o estado nutricional das culturas, comparando-os com o teor padrão estabelecido para cada nutriente para uma determinada cultura. De acordo com Silva et al. (2002), para que a bananeira 'Prata anã' irrigada alcance alta produção, a faixa de suficiência do $\mathrm{K}$ no tecido foliar deve ser de 2,7-3,5 dag kg-1 e o nível crítico de 3,0 dag $\mathrm{kg}^{-1}$.

Este trabalho teve por objetivos comparar os efeitos de duas fontes de $\mathrm{K}$ (cloreto de potássio e sulfato de potássio) sobre a produção, estimar as doses de $\mathrm{K}$ para obter a máxima eficiência física e econômica, bem como determinar o nível crítico de $\mathrm{K}$ na folha da bananeira 'Prata anã' (AAB) irrigada.

\section{MATERIAL E MÉTODOS}

O experimento foi realizado em Latossolo VermelhoAmarelo (LVA), textura média, no município de Jaíba-MG, localizado na região semiárida do norte de Minas Gerais, Brasil. A temperatura e a pluviosidade médias anuais nesta região são de $26^{\circ} \mathrm{C}$ e $800 \mathrm{~mm}$, respectivamente. Essa região está sob um clima do tipo Aw, segundo a classificação de Köppen (Moreira, 1985).

Antes das aplicações dos adubos e do plantio das mudas de bananeira, o solo foi amostrado na profundidade de 0 a 0,20 m, sendo determinados os valores de $\mathrm{pH}$ em água e os teores de matéria orgânica (MO), $\mathrm{P}, \mathrm{K}, \mathrm{Ca}, \mathrm{Mg}$, Al, e H+Al, conforme Embrapa (1997) (Tabela 1).

Para o plantio foram utilizadas mudas de bananeira Prata Anã (AAB), obtidas de cultura de tecido. O plantio das mudas foi realizado em sulcos, com profundidades de 
$0,20 \mathrm{~m}$, no espaçamento de $2,5 \mathrm{~m}$ x 3,0 m, totalizando 1333 mudas $\mathrm{ha}^{-1}$. As parcelas do experimento foram constituídas de 20 plantas de bananeira, sendo consideradas úteis as seis plantas centrais. O experimento foi implantado em abril de 2006 e finalizado em julho de 2009.

A condução e o manejo da bananeira foram realizados, utilizando-se uma família em cada touceira de bananeira (plantas mãe: $1^{\circ}$ ciclo; filha: $2^{\circ}$ ciclo e neta: $3^{\circ}$ ciclo). $\mathrm{O}$ experimento foi irrigado, utilizando-se o sistema de microaspersão. O manejo da irrigação foi realizado por meio de medidas da evaporação do tanque classe A, conforme descrito por Costa et al. (1999). O controle da sigatokaamarela foi realizado com aplicações de fungicidas, de acordo com recomendação de Pereira et al. (1999).

As adubações de plantio, de crescimento e de frutificação da bananeira foram realizadas com base nas análises de solo e de folhas, de acordo com recomendações de Silva et al. (1999). Nessas adubações foram aplicados fósforo no plantio e a cada seis meses; nitrogênio mensalmente, magnésio a cada três meses e, zinco e boro, a cada quatro meses. Para aplicar esses nutrientes foram utilizados como fontes o superfosfato simples, a ureia, o sulfato de magnésio, o sulfato de zinco e o ácido bórico, respectivamente. Esses adubos foram aplicados manualmente, em semicírculo, a 0,40 m distante das plantas.

Os tratamentos foram originados do fatorial ( $4 \times 2)$, sendo quatro doses de $\mathrm{K}(0,400,800$ e $1200 \mathrm{~kg} / \mathrm{ha}$ ano de $\mathrm{K}_{2} \mathrm{O}$ ) e duas fontes de $\mathrm{K}$ (Cloreto de potássio e Sulfato de potássio), gerando oito tratamentos. Estes foram distribuídos em blocos ao acaso, com quatro repetições. As doses de $\mathrm{K}$ foram escolhidas com base nas recomendações de adubação de Silva et. al. (1999) e nos resultados apresentados por Silva et. al. (2003). A adubação potássica iniciou-se no terceiro mês após o plantio das mudas e foi aplicada mensalmente.

A calagem foi calculada para elevar a saturação de bases do solo a 70\%. O calcário dolomítico utilizado apresentou PRNT de $100 \%$ e foi aplicado trinta dias antes do plantio da bananeira, em toda a área, e incorporado ao solo à profundidade de $0,20 \mathrm{~m}$.

O enxofre (S) do sulfato de potássio foi compensado, substituindo-se a ureia como fonte de nitrogênio pelo sulfato de amônio, nas parcelas que não receberam o sulfato de potássio.
Nas plantas em início de emissão do cacho de banana, foram coletadas a 3 a folha a partir do ápice, retirando-se 0,10 $\mathrm{m}$ do centro do limbo de cada folha, eliminando-se a nervura central. O material colhido foi colocado para secar em estufa com circulação forçada de ar, a $70^{\circ} \mathrm{C}$, durante 72 horas. O material, após seco e moído, foi analisado e o teor de $\mathrm{K}$ foi determinado, conforme método descrito por Malavolta et al. (1997).

Os cachos de banana das plantas de cada parcela útil, quando atingiram o ponto de colheita, foram colhidos, despencados e pesados. Avaliou-se a produção de bananas, o comprimento e a massa do fruto mediano da $2^{\text {a }}$ penca de cada cacho, em três ciclos de produção. Os dados obtidos foram submetidos às análises de variância (Teste F) e ajustes de regressões. Para a escolha do modelo de regressão, considerou-se o nível de significância de $5 \%$ de probabilidade e o maior coeficiente de determinação $\left(\mathrm{R}^{2}\right)$.

Para obter a máxima eficiência física (MEF), igualouse a zero a primeira derivada das regressões quadráticas ajustadas entre a produção de bananas, em função das doses de $\mathrm{K}_{2} \mathrm{O}$, com a utilização de $\mathrm{KCl}_{\text {e }} \mathrm{K}_{2} \mathrm{SO}_{4}$.

$\frac{d \hat{y}}{d x}=0$

Para obter a máxima eficiência econômica (MEE), igualou-se a primeira derivada das regressões quadráticas ajustadas entre a produção de bananas em função das doses de $\mathrm{K}_{2} \mathrm{O}$ à relação de preços do $\mathrm{K}_{2} \mathrm{O}$ e da banana.

$\frac{d \hat{y}}{d x}=\frac{P x}{P y}\left(P x\right.$ é o preço do $\mathrm{kg}$ de $\mathrm{K}_{2} \mathrm{O}$ contido no $\mathrm{KCl}$ e $\mathrm{K}_{2} \mathrm{SO}_{4}$ e $P y$ é o preço do kg de banana):

Preço do $\mathrm{kg}$ de $\mathrm{K}_{2} \mathrm{O}$ contido no $\mathrm{KCl}=\mathrm{R} \$ 2,84$ e no $\mathrm{K}_{2} \mathrm{SO}_{4}=\mathrm{R} \$ 5,20$

Preço do $\mathrm{kg}$ de banana $=\mathrm{R} \$ 0,73$ (preço referente à média de preços do ano de 2010).

\section{RESULTADOS E DISCUSSÃO}

De acordo com a análise de variância, não foram observadas diferenças significativas entre os efeitos do $\mathrm{KCl}$ e $\mathrm{K}_{2} \mathrm{SO}_{4}$ sobre a produção da bananeira, o comprimento e a massa do fruto no $1^{\circ}, 2^{\circ}$ e $3^{\circ}$ ciclos de produção.

Tabela 1. Resultados das análises químicas do Latossolo Vermelho-Amarelo (LVA)

\begin{tabular}{|c|c|c|c|c|c|c|c|c|c|c|}
\hline \multirow[t]{2}{*}{ Solo } & \multirow[t]{2}{*}{${ }^{1} \mathrm{pH}$} & ${ }^{2} \mathrm{MO}$ & ${ }^{3} \mathbf{P}$ & $\mathbf{K}$ & ${ }^{4} \mathbf{C a}^{2+}$ & $\mathbf{M g}^{2+}$ & $\mathrm{Al}^{3+}$ & ${ }^{5} \mathrm{H}+\mathrm{Al}$ & $\mathbf{T}$ & \multirow{2}{*}{$\frac{\mathbf{V}}{\%}$} \\
\hline & & dag $\mathrm{dm}^{-3}$ & \multicolumn{2}{|c|}{$\mathrm{mg} \mathrm{dm}^{-3}$} & \multicolumn{5}{|c|}{$\mathrm{cmol}_{\mathrm{c}} \mathrm{dm}^{-3}$} & \\
\hline LVA & 5,0 & 1,2 & 8,1 & 58 & 1,3 & 1,2 & 0,0 & 2,7 & 5,3 & 50 \\
\hline
\end{tabular}

${ }^{1} \mathrm{pH}$ em água; ${ }^{2}$ Matéria orgânica (oxidação com dicromato de potássio em meio sulfúrico e titulação com sal de Mohr); ${ }^{3} \mathrm{P}$ e $\mathrm{K}$ extraídos com extrator Melich-1; ${ }^{4} \mathrm{Ca}^{+2}, \mathrm{Mg}^{+2}$ e $\mathrm{Al}^{+3}$ (solução normal de $\mathrm{KCl}$ ) e ${ }^{5} \mathrm{H}+\mathrm{Al}$ (Solução SMP). 
No $1^{\circ}$ ciclo, a bananeira não respondeu à aplicação de K. Uma das características da bananeira 'Prata anã' é apresentar baixa produtividade no $1^{\circ}$ ciclo em relação aos ciclos subsequentes, e, consequentemente, exigir menores quantidades de nutrientes. Assim, é pouco provável obter resposta da bananeira à aplicação de $\mathrm{K}$ no $1^{\circ}$ ciclo, principalmente quando cultivada em solo que apresenta teor de $\mathrm{K}$ disponível classificado entre médio e alto, conforme Alvarez et al. (1999). Os resultados obtidos nos trabalhos realizados por Borges et al. (1997) e Silva \& Pereira (2011) confirmam essa observação. O teor de K disponível no solo utilizado no presente trabalho (Tabela 1) foi classificado como médio.

A bananeira, nos $2^{\circ}$ e $3^{\circ}$ ciclos de produção, respondeu à aplicação de K. O modelo de regressão que melhor se ajustou foi o quadrático (Figuras $1 \mathrm{~A} \mathrm{e} 1 \mathrm{~B}$ ). No $2^{\circ}$ ciclo de produção, as doses de $\mathrm{K}$ para obter a MEF, nos tratamentos em que se utilizaram o $\mathrm{KCl}$ e $\mathrm{K}_{2} \mathrm{SO}_{4}$, foram de 827 e $817 \mathrm{~kg} \mathrm{ha}^{-1}$ ano ${ }^{-1}$ de $\mathrm{K}_{2} \mathrm{O}$, respectivamente. Já, no $3^{\circ}$ ciclo, as doses obtidas foram de 835 e 795 , respectivamente.

No estudo realizado por Silva et al. (2003), em solo argiloso com alto teor de $\mathrm{K}\left(210 \mathrm{mg} \mathrm{dm}^{-3}\right)$, os autores verificaram que a dose de $\mathrm{K}$ para obter a máxima eficiência física no $4^{\circ}$ ciclo da bananeira 'Prata anã' foi de $963 \mathrm{~kg}$ ha ano de $\mathrm{K}_{2} \mathrm{O}$, que promoveu aumento de $11 \%$ na produção de banana, em relação à testemunha. Já Santos et. al. (2009) verificaram que a aplicação de potássio, na forma de $\mathrm{KCl}$, em solo com baixo teor de $\mathrm{K}\left(31,2 \mathrm{mg} \mathrm{dm}^{-3}\right)$, elevou a produção da bananeira 'Prata anã' linearmente. Segundo estes autores, a maior dose estudada, $470 \mathrm{~kg} \mathrm{ha}^{-1} \mathrm{de}_{2} \mathrm{O}$, não foi suficiente para a inflexão da curva de resposta. Entretanto, Silva \& Pereira (2011) verificaram efeito quadrático do K sobre a produção, no $2^{\circ}$ ciclo da bananeira 'Prata anã' cultivada em solo com teor de $60 \mathrm{mg} \mathrm{dm}^{-3} \mathrm{de}$ $\mathrm{K}$. A dose estimada para a máxima eficiência física foi de $860 \mathrm{~kg}$ ha ano de $\mathrm{K}_{2} \mathrm{O}$.

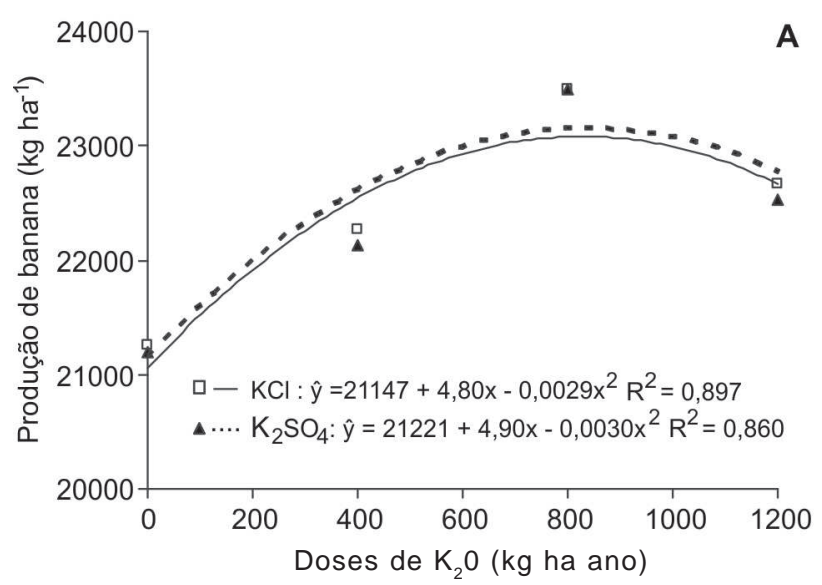

Nos $2^{\circ}$ e $3^{\circ}$ ciclos de produção, as doses estimadas para a máxima eficiência econômica da bananeira foram de 157 e $670 \mathrm{~kg} / \mathrm{ha}$ ano de $\mathrm{K}_{2} \mathrm{O}$, respectivamente, utilizando-se o $\mathrm{KCl}$ como fonte. Para $\mathrm{o}_{2} \mathrm{SO}_{4}$, a relação $\frac{d \hat{y}}{d x}=\frac{P x}{P y}$, no $2^{\circ}$ ciclo, foi negativa, indicando a inviabilidade econômica da aplicação desse fertilizante como fonte de $\mathrm{K}$, nesse ciclo da bananeira. Já, no $3^{\circ}$ ciclo, a dose estimada foi $528 \mathrm{~kg} / \mathrm{ha}$ ano de $\mathrm{K}_{2} \mathrm{O}$. Como os preços do $\mathrm{kg}$ de $\mathrm{K}_{2} \mathrm{O}$ contido nos $\mathrm{KCl}_{\mathrm{K}} \mathrm{K}_{2} \mathrm{SO}_{4}$ foram de $\mathrm{R} \$ 2,84 \mathrm{e}$ 5,20 , respectivamente, os custos totais para aplicar K, utilizando-se $\mathrm{KCl} \mathrm{e} \mathrm{K}_{2} \mathrm{SO}_{4}$, no $3^{\circ}$ ciclo, foram de $\mathrm{R} \$ 1.903,00$ e 2.746,00, respectivamente, concluindo-se que o $\mathrm{KCl}$ apresentou-se com maior viabilidade econômica para ser utilizado na bananeira como fonte de $\mathrm{K}$.

$\mathrm{O}$ solo onde foi realizado o presente trabalho apresentou teor de $\mathrm{K}$ disponível de $58 \mathrm{mg} \mathrm{dm}^{-3}$ (Tabela 1) e a dose de $\mathrm{K}_{2} \mathrm{O}$ estimada para a máxima eficiência econômica, no $3^{\circ}$ ciclo da bananeira, utilizando-se o $\mathrm{KCl}$, foi de $670 \mathrm{kkg} /$ ha ano de $\mathrm{K}_{2} \mathrm{O}$, para obter produtividade de $34 \mathrm{tha}^{-1}$ ano ${ }^{1}$. Esse valor está próximo de $700 \mathrm{~kg} \mathrm{de}_{2} \mathrm{O} \mathrm{ha}^{-1} \mathrm{ano}^{-1}$, que é a dose recomendada por Silva \& Borges (2008) para aplicar em bananeira cultivada em solo com teor de K disponível igual ou menor que $58 \mathrm{mg} \mathrm{dm}^{-3} \mathrm{e} \mathrm{com}$ produtividade esperada entre 30 e 50 t/ha ano.

De acordo com a análise de variância, observou-se efeito significativo da aplicação de $\mathrm{K}$ no solo sobre o comprimento dos frutos no $2^{\circ} \mathrm{e} 3^{\circ}$ ciclos de produção. $\mathrm{O}$ modelo quadrático foi o que mais se ajustou (Figura $2 \mathrm{~A} \mathrm{e}$ 2B). A massa do fruto de banana não foi influenciada pela aplicação das doses de K no solo. De acordo com Lahav \& Tuner (1983), bananeiras cultivadas em solos com baixo teor de $\mathrm{K}$ produzem cachos de banana com frutos magros e pequenos.

A partir das doses de $\mathrm{K}$ que proporcionaram a MEF e MEE e da substituição desses valores nas equações que

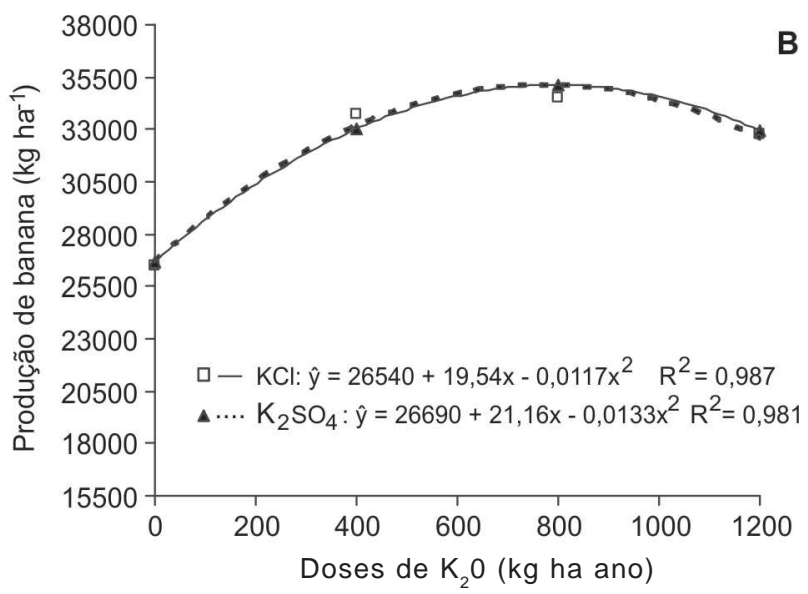

Figura 1. Produção da bananeira 'Prata anã' em função de doses de $\mathrm{K}$ aplicadas na forma de $\mathrm{KCl}_{\text {e }} \mathrm{K}_{2} \mathrm{SO}_{4}$, no $2^{\circ}$ (A) e $3^{\circ}$ (B) ciclos.

Rev. Ceres, Viçosa, v. 58, n.6, p. 817-822, nov/dez, 2011 
relacionam teor de $\mathrm{K}$ foliar com doses de $\mathrm{K}$ aplicadas (Tabela 2), estimaram-se os níveis críticos foliares de $\mathrm{K}$, nos $2^{\circ}$ e $3^{\circ}$ ciclos da bananeira. Considerou-se apenas o $\mathrm{KCl}$, já que não houve diferenças dos efeitos entre as duas fontes de $\mathrm{K}$ sobre a produção da bananeira e que o $\mathrm{KCl}$ apresentou-se com maior viabilidade econômica para ser utilizado. O valor do nível crítico obtido, considerando-se as doses que proporcionaram a MEF, foi de 2,90 dag $\mathrm{kg}^{-1}$ para o $2^{\circ}$ e $3^{\circ}$ ciclos e, para as doses que proporcionaram a MEE, os valores foram de 2,41 e 2,80 dag $\mathrm{kg}^{-1}$, para os $2^{\circ}$

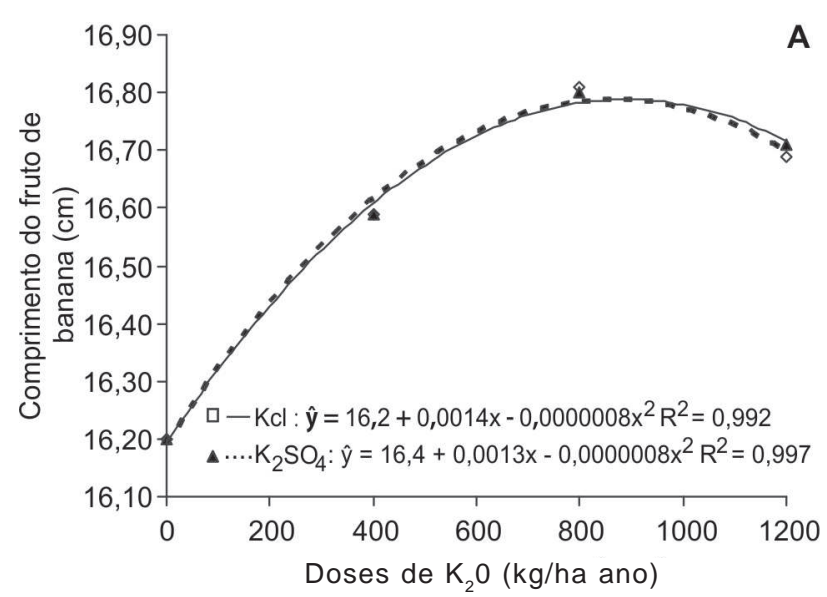

e $3^{\circ}$ ciclos, respectivamente. O nível crítico obtido por Silva \& Pereira (2011), para obter a MEF no $2^{\circ}$ ciclo da bananeira 'Prata anã', foi de 2,95 dag $\mathrm{kg}^{-1}$, próximo do estimado neste trabalho. Fatores como clima, tipo de solo, práticas de manejo, entre outros, influenciam no valor de nível crítico dos nutrientes nas folhas das plantas.

O teor foliar de K correlacionou-se com a produção de banana (Tabela 3), ou seja, verificou-se uma relação bem definida entre o aumento do teor de $\mathrm{K}$ nas folhas da bananeira e o aumento de produção nos $2^{\circ}$ e $3^{\circ}$ ciclos.

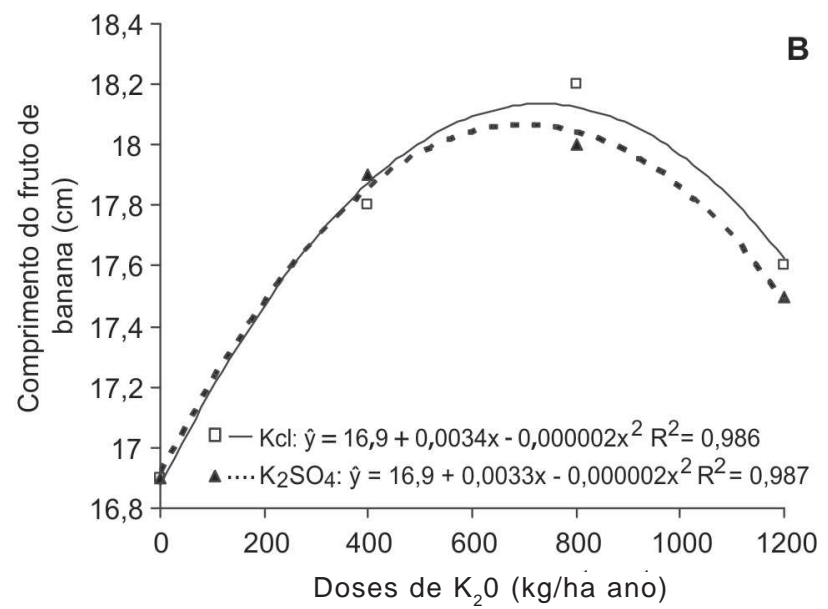

Figura 2. Comprimento do fruto de banana em função de doses de $\mathrm{K}$ aplicadas na forma de $\mathrm{KCl}_{\text {e }} \mathrm{K}_{2} \mathrm{SO}_{4}$, no $2^{\circ}$ (A) e $3^{\circ}$ (B) ciclos de produção da bananeira 'Prata anã'.

Tabela 2. Regressões ajustadas entre o teor de K na terceira folha da bananeira 'Prata anã' em função de doses de $\mathrm{K}_{2} \mathrm{O}$ na forma de $\mathrm{KCl}$ e $\mathrm{K}_{2} \mathrm{SO}_{4}$ no $1^{\circ}, 2^{\circ}$ e $3^{\circ}$ ciclos de produção

\begin{tabular}{ll}
\hline \multicolumn{1}{c}{ Regressões } \\
\hline $1^{\circ}$ ciclo $\mathrm{KCl}: \hat{y}=2,34+0,0005 \mathrm{x}$ & $\mathrm{R}^{2}=0,894$ \\
$2^{\circ}$ ciclo $\mathrm{KCl}: \hat{y}=2,30+0,0007 \mathrm{x}$ & $\mathrm{R}^{2}=0,923$ \\
$3^{\circ}$ ciclo $\mathrm{KCl}: \hat{\mathrm{y}}=2,32+0,0007 \mathrm{x}$ & $\mathrm{R}^{2}=0,933$ \\
$1^{\circ}$ ciclo $\mathrm{K}_{2} \mathrm{SO}_{4}: \hat{y}=2,29+0,0006 \mathrm{x}$ & $\mathrm{R}^{2}=0,931$ \\
$2^{\circ}$ ciclo $\mathrm{K}_{2} \mathrm{SO}_{4}: \hat{y}=2,32+0,0006 \mathrm{x}$ & $\mathrm{R}^{2}=0,938$ \\
$3^{\circ}$ ciclo $\mathrm{K}_{2} \mathrm{SO}_{4}: \hat{\mathrm{y}}=2,40+0,0005 \mathrm{x}$ & $\mathrm{R}^{2}=0,940$ \\
\hline
\end{tabular}

\section{CONCLUSÕES}

Não houve diferenças entre os efeitos do $\mathrm{KCl}_{\text {e }} \mathrm{K}_{2} \mathrm{SO}_{4}$ sobre a produção da bananeira.

$\mathrm{O} \mathrm{KCl}$ apresentou maior viabilidade econômica para ser utilizado como fonte de K para a bananeira em relação ao $\mathrm{K}_{2} \mathrm{SO}_{4}$.

As doses estimadas para a MEE da bananeira nos $2^{\circ} \mathrm{e}$ $3^{\circ}$ ciclos de produção, utilizando-se o $\mathrm{KCl}$, foram de $157 \mathrm{e}$ $670 \mathrm{~kg} / \mathrm{ha}$ ano de $\mathrm{K}_{2} \mathrm{O}$, respectivamente.

Os níveis críticos foliares de $\mathrm{K}$ obtidos nos $2^{\circ}$ e $3^{\circ}$ ciclos de produção para obter a MEF foi de 2,90 dag $\mathrm{kg}^{-1}$ e para a MEE foram de 2,41 e 2,80 dag kg ${ }^{-1}$, respectivamente.
Tabela 3. Correlação de Pearson entre o teor de $\mathrm{K}$ foliar e a produção da bananeira 'Prata anã' nos $2^{\circ}$ e $3^{\circ}$ ciclos

\begin{tabular}{|c|c|c|c|}
\hline \multicolumn{4}{|c|}{ Correlação de Pearson } \\
\hline \multicolumn{4}{|c|}{ Ciclos } \\
\hline \multicolumn{2}{|c|}{$2^{\circ}$ ciclo } & \multicolumn{2}{|c|}{$3^{\circ}$ ciclo } \\
\hline $\begin{array}{l}\mathrm{KCl} \\
0,731^{* *}\end{array}$ & $\begin{array}{c}\mathrm{K}_{2} \mathrm{SO}_{4} \\
0,769 * *\end{array}$ & $\begin{array}{c}\mathrm{KCl} \\
0,708 * *\end{array}$ & $\begin{array}{c}\mathrm{K}_{2} \mathrm{SO}_{4} \\
0,882 * *\end{array}$ \\
\hline
\end{tabular}

\section{REFERÊNCIAS}

Alvarez V VH, Novais RF, Barros NF, Cantarutti RB \& Lopes AS (1999) Interpretação dos resultados das análises de solos. In: Ribeiro AC, Guimarães PTG \& Alvarez V VH (Eds.). Recomendações para o uso de corretivos e fertilizantes em Minas Gerais. $5^{\mathrm{a}}$ aproximação. Viçosa. Universidade Federal de Viçosa. p.25-32.

Borges AL, Silva JTA \& Oliveira SL (1997) Adubação nitrogenada e potássica para bananeira c.v Prata anã irrigada: produção e qualidade dos frutos no primeiro ciclo. Revista Brasileira de Fruticultura, 19:179-184.

Costa EL.; Maeno, P.; Albuquerque, PEP (1999) Irrigação da bananeira. Informe Agropecuário, Belo Horizonte, 20:67-72.

Embrapa - Centro Nacional de Pesquisas de solos (1997) Manual de métodos de análise de solo. $2^{\mathrm{a}}$ ed. Rio de Janeiro, Embrapa Solos. 212 p.

Rev. Ceres, Viçosa, v. 58, n.6, p. 817-822, nov/dez, 2011 
Ernani PR, Almeida JA \& Santos, FC (2007) Potássio. In: Novais RF, Alvarez V VH, Barros NF, Fontes RLF, Cantaruti RB \& Neves JCL (Eds.) Fertilidade do solo. $1^{\text {a }}$ ed. Viçosa, SBCS. p. 551-594.

Lahav E, Turner DW (1983) Banana nutrition, Bern, International Potash Institute. 62p. (IPI. Bulletin, 7).

Malavolta E, Vitti GC \& Oliveira AS (1997) Avaliação do estado nutricional das plantas: princípios e aplicações. $2^{\mathrm{a}}$ ed. Piracicaba, Potafos. 319p.

Meurer EJ (2006) Potássio. In: Manilo Silvestre Fernandes (Ed.). Nutrição mineral de plantas. $1^{\mathrm{a}}$ ed.Viçosa, SBCS. p.281-298.

Moreira IAG (1985) Geografia Geral e do Brasil. São Paulo, Moderna. 230p.

Pereira LV, Cordeiro ZJM, Figueira AR, MATOS AP (1999) Doenças da bananeira. Informe Agropecuário, Belo Horizonte, 20:37-46.

Pinto JM, Faria CMB, Silva DJ, Feitosa Filho JC (2005) Doses de nitrogênio e potássio aplicadas via fertirrigação em bananeira. Irriga, 10:46-52.

Santos VP, Fernandes PD, Melo AS, Sobral LF, Brito MEB, Dantas JDM \& Bonfim LV (2009) Fertirrigação da bananeira cv. PrataAnã com N e K em um Argissolo Vermelho-Amarelo. Revista Brasileira de Fruticultura, 31:567-573.

Silva, IP (2010) Adubação com magnésio e potássio em bananeira "Prata anã" cultivada em área irrigada com água calcária no Norte de Minas. Dissertação de Mestrado. Universidade Federal de Lavras, Lavras. 59 p.
Silva JTA, Borges AL \& Malburg, JL (1999) Solos, adubação e nutrição da bananeira. Informe Agropecuário, 20:21-36.

Silva JTA, Borges AL, Dias MSC, Costa EL \& Prudêncio JM (2002) Diagnóstico nutricional da bananeira 'Prata-Anã' para o Norte de Minas Gerais. Belo Horizonte, EPAMIG. 16p. (Boletim Técnico, 70).

Silva JTA, Borges, AL, Carvalho JG \& Damasceno JEA (2003) Adubação com potássio e nitrogênio em três ciclos de produção da bananeira Prata Anã. Revista Brasileira de Fruticultura, 25:152-155

Silva JTA \& Borges AL (2008) Solos, nutrição mineral e adubação da bananeira. Informe Agropecuário, 29:23-34.

Silva JTA \& Pereira RD (2011) Produção da bananeira 'Prata anã' (ABB) em função da adubação com $\mathrm{K}$, em dois ciclos de produção. In: $33^{\circ}$ Congresso Brasileiro de Ciência do Solo, Uberlândia. Anais, SBCS. CD ROM.

Silva MAG, Boareto AE, Fernandes HG, Boareto R, Melo AMT \& Scivittaro WB (2001) Características químicas de um Latossolo adubado com uréia e cloreto de potássio em ambiente protegido. Scientia Agrícola, 58:561-566.

Sousa VF, Veloso MEC, Vasconcelos LFL, Ribeiro VQ, Souza, VAB \& Albuquerque Júnior BS (2004) Nitrogênio e potássio via água de irrigação nas características de produção da bananeira Grand Naine. Pesquisa Agropecuária Brasileira, 39:865-869. 